\title{
Modeling Neck Mobility in Fossil Turtles
}

\author{
INGMAR WERNEBURG ${ }^{1,2,3 *}$, \\ JULIANE K. HINZ ${ }^{1}$, \\ MICHAELA GUMPENBERGER ${ }^{4}$, \\ VIRGINIE VOLPATO ${ }^{5}$, \\ NIKOLAY NATCHEV ${ }^{6,7}$, AND \\ WALTER G. JOYCE ${ }^{1,8}$
}

${ }^{1}$ Fachbereich Geowissenschaften der Eberhard Karls Universität Tübingen, Tübingen, Germany ${ }^{2}$ Museum für Naturkunde, Leibniz Institute for Research on Evolution and Biodiversity, Berlin, Germany

${ }^{3}$ Paläontologisches Institut und Museum der Universität Zürich, Zürich, Switzerland

${ }^{4}$ Diagnostic Imaging, University of Veterinary Medicine Vienna, Vienna, Austria

${ }^{5}$ Paläoanthropologie und Messelforschung/Mammalogie, Senckenberg Gesellschaft für Naturforschung, Frankfurt am Main, Germany

${ }^{6}$ Department of Integrative Zoology, University of Vienna, Vienna, Austria

${ }^{7}$ Faculty of Natural Science, Shumen University, Bulgaria, Shumen 9712, Univeristetska str. 115

${ }^{8}$ Department of Geoscience, University of Fribourg, Fribourg, Switzerland

\begin{abstract}
Turtles have the unparalleled ability to retract their heads and necks within their shell but little is known about the evolution of this trait. Extensive analysis of neck mobility in turtles using radiographs, CT scans, and morphometry reveals that basal turtles possessed less mobility in the neck relative to their extant relatives, although the anatomical prerequisites for modern mobility were already established. Many extant turtles are able to achieve hypermobility by dislocating the central articulations, which raises cautions about reconstructing the mobility of fossil vertebrates. A 3D-model of the Late Triassic turtle Proganochelys quenstedti reveals that this early stem turtle was able to retract its head by tucking it sideways below the shell. The simple ventrolateral bend seen in this stem turtle, however, contrasts with the complex double-bend of extant turtles. The initial evolution of neck retraction therefore occurred in a near-synchrony with the origin of the turtle shell as a place to hide the unprotected neck. In this early, simplified retraction mode, the conical osteoderms on the neck provided further protection.
\end{abstract}

In addition to their shell and their unusual skull and shoulder region, turtles (Testudinata) are unique in regard to the mobility of their necks (Rieppel, 2008; Nagashima et al., 2009). In contrast to all other vertebrates, turtles are able to hide their head and neck inside the body wall (i.e., inside the shell) in order to protect these structures against predators. Among extant turtles, two monophyletic clades can be recognized, which, among other features, differ in the way they retract their head and neck inside the shell (Gaffney, '75). Pleurodires fold their head and neck sideward in a horizontal plane anterior to the rib cage, whereas
Grant sponsor: Deutsche Forschungsgemeinschaft; grant number: J0 928/1.

*Correspondence to: Ingmar Werneburg, Museum für Naturkunde, Leibniz Institute for Research on Evolution and Biodiversity, Berlin, Germany.

E-mail: i.werneburg@gmail.com 
cryptodires retract their neck within the rib cage in a vertical plane. High neck mobility is otherwise known for many birds (Weisgram and Zweers, '87) and has been reconstructed for advanced sauropodomorphs (Taylor et al., 2009). Although some birds can retract their heads and necks over their bodies, only turtles can retract the head/neck-apparatus within the confines of the body wall.

The cervical column of turtles consists of eight vertebrae (Williams, '50; Müller et al., 2010) and a great diversity of vertebral morphology can be recognized that enables various types of movement (Vaillant, 1881, 1883; Ogushi, '11; Williams, '50; Hoffstetter and Gasc, '69; Herrel et al., 2008). To date, research on the neck has been restricted to documenting cervical variation (Williams, '50), investigating the myology of the neck (Werneburg, 2011), understanding the general mechanics of neck retraction (Weisgram and Splechtna, '90), and exploring the interactions of neck-movement with feeding (Herrel et al., 2008). However, virtually no efforts have been made to reconstruct neck mobility among fossil turtles beyond the tacit assumption that the amphicoelous vertebrae of basal turtles did not permit great mobility (Hay, '08; Młynarski, '76; Williams, '50). Many basic questions regarding the origin and evolution of neck retraction mechanisms therefore remain unanswered.

How great was the mobility of the neck of fossil stem turtles? When and how did the neck retraction mechanism and the great neck mobility of extant taxa evolve, and did the drastically different modes of retraction in pleurodires and cryptodires evolve independently from one another? Which anatomical changes are associated with these important evolutionary innovation? Does the mobility of the neck of extant turtles have any implication regarding the mobility of extinct taxa? We tackle these questions by analyzing the vertebrae of several extant and fossil turtle species with the help of angle measurements and by modeling the mobility of the best-known Triassic fossil turtle, Proganochelys quenstedti (Gaffney, '90). The mobility of living turtle specimens was analyzed with the help of computed tomography. Taphonomic distances (i.e., the difference between the maximum mechanically possible and observed movement) were calculated to better reconstruct mobility in the necks of fossil turtles. Throughout this article, the term "flexion" is used to refer to U-shaped dorsal, ventral, and lateral bending of the neck, whereas the term "retraction" is used to refer to the withdrawal of the neck within the confines of the body wall.

\section{METHODS}

\section{Specimens}

In total, the neck vertebrae of five extinct and 35 extant turtle species were studied. Two non-turtle species were used for comparison (Fig. 1). The list of fossil and extant turtle skeletons used herein, including morphometric measurements, is provided in Supplementary Table S1 whereas living turtles are listed in
Supplementary Table S2. Additional data, including angle measurements and images, were taken from the literature (Supplementary Table S3).

\section{Radiographs and Fluoroscopy of Living Animals}

Fluoroscopy of different neck postures of 29 animals (Table S2), presented to the clinic with reasons unreleated to and not interfering with this study, were performed using a Siemens Axiom Iconos R200 (Siemens AG, München, Deutschland, Germany) at the University of Veterinary Medicine in Vienna (Fig. 2).

In order to not unreasonably stimulate or manipulate the animals, focus was placed on the maximum retraction of each specimen and only one radiograph was produced for each animal. If the animals were cooperative and curious to attractants (e.g., food, compare Fig. 2C), additional images were taken for other positions of the neck (Supplementary Table S7).

\section{CT-Scans of Living Animals}

Most individuals used for fluoroscopy underwent an additional diagnostic CT examination using a Siemens Somatom Emotion multislice scanner (Siemens AG) at $130 \mathrm{kV}, 80 \mathrm{~mA}, 1.0 \mathrm{sec}$ (rotation time) and $0.6 \mathrm{~mm}$ thick slices. The specimens were kept at $25-30^{\circ} \mathrm{C}$ temperature and anesthetized with medetomidine $0.05 \mathrm{mg} / \mathrm{kg}$ BW and ketamine $5 \mathrm{mg} / \mathrm{kg}$ body mass (intramuscular) (Supplementary Table S2).

The head and neck of each specimen were manually flexed to the physiologically (1) most extended (Fig. 2J,N, Supplementary Table S8A), (2) most retracted (Fig. 2M, Supplementary Table S8B, C), (3) most lateral (Supplementary Table S8D,E), (4) most dorsal (Fig. 2K,0, Supplementary Table S8F), and (5) most ventral position (Fig. 2L,P, Supplementary Table S8G). The living animals were handled very carefully; their heads and necks were not overstretched to avoid strangulation of the neck plexus and to not risk their health. This method can only provide an approximation of the actual maximal mobility in living animals, as muscle forces, such as those provided by musculus retrahens capiticollique (Werneburg, 2011) or by intervertebral muscles, certainly allow for slightly larger retraction or flexion of the neck. The above mentioned radiographic studies (Supplementary Table S7) therefore provide an important comparison.

The CT-data was reconstructed with the surface view tool of Amira, surface files (obj/ply) were exported to MeshLab, and screenshots taken from that software were analyzed using Image J (http://meshlab.sourceforge.net/).

\section{Angle Measurements}

For macerated and fossil specimens, as well as for radiographed and CT-scanned living animals, the amount of mobility was measured between adjacent vertebrae using a suite of different techniques (Supplementary Tables S4, S7, and S8). For the macerated and fossil specimens, digital photographs were taken 


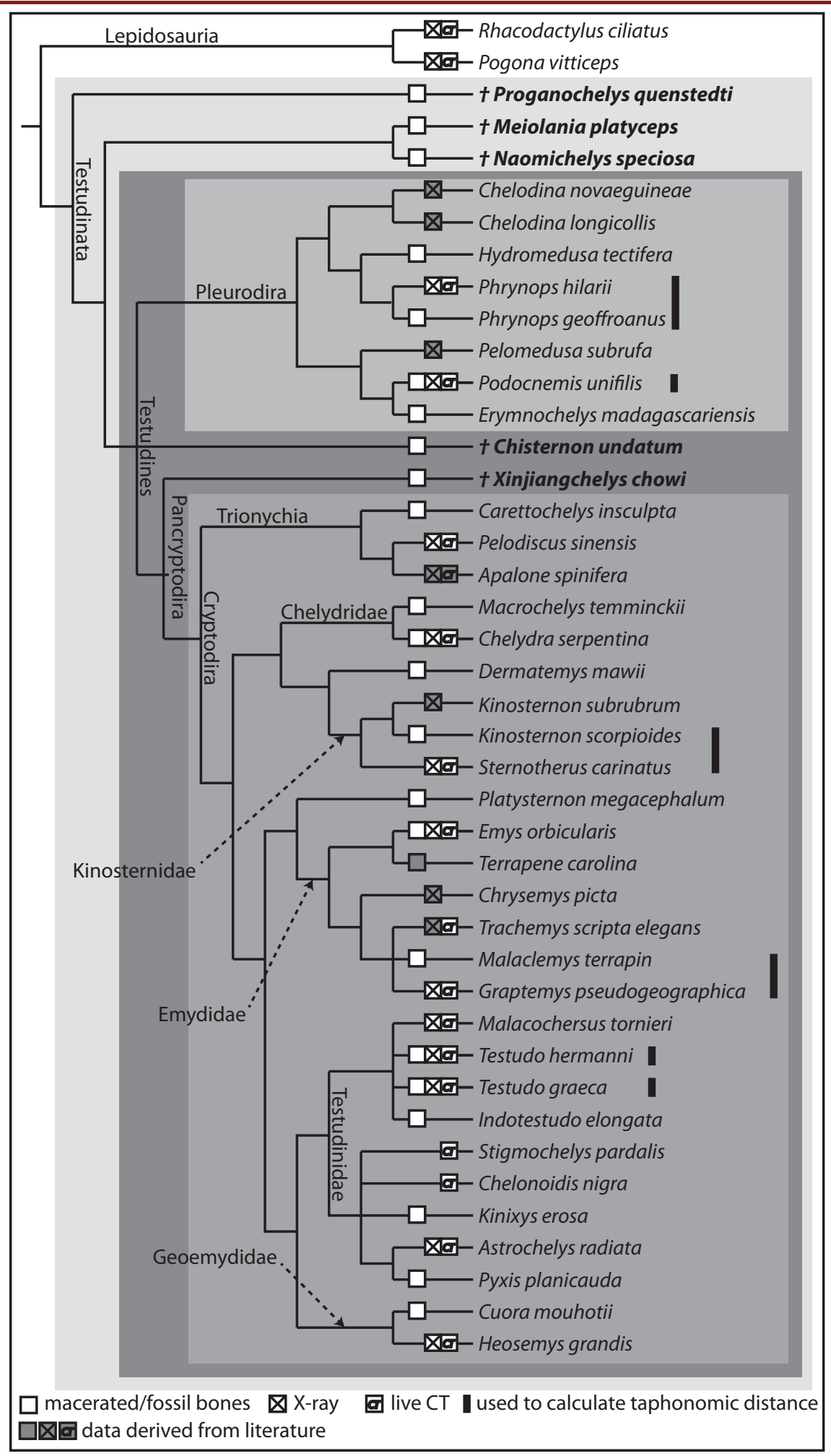

Figure 1. Fossil and living turtle species analyzed in the present study. Phylogenetic arrangements follow Joyce (2007) and Anquentin (2012) for extinct taxa and Thomson and Shaffer (2010) for extant taxa. 


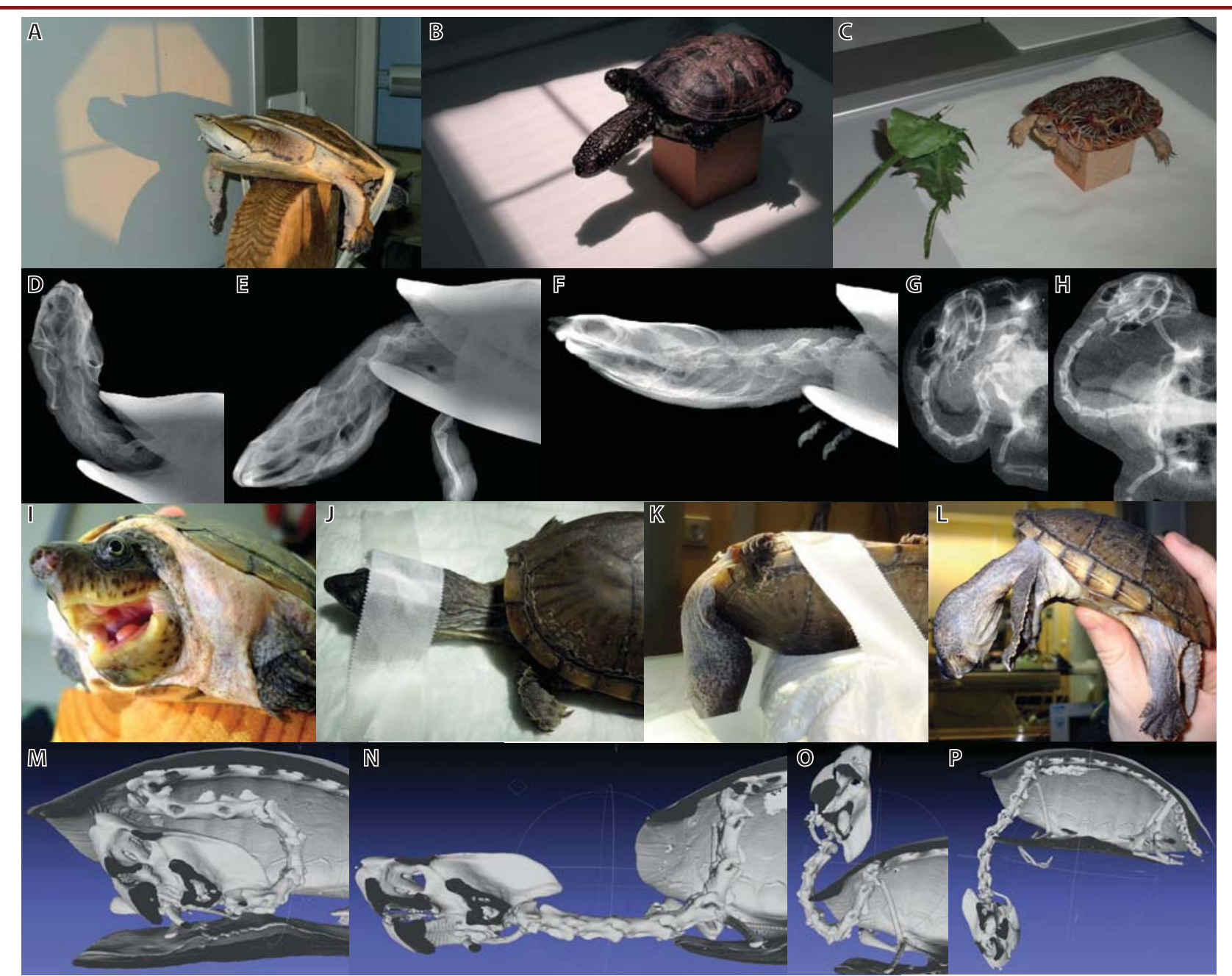

Figure 2. Illustration of select methods. (A-C, I) Setup for fluoroscopy; (D-H) radiographs; (J-L) setup for CT-scans; and (M-P) CT-scans (visualized via Avizo and MeshLab). (A, D-F) Phrynops hilarii (IW1121); (B) Emys orbicularis (IW1116); (C) Malacochersus tornieri (IW1119); (G-H) Chelodina novaeguineae (IW1168), with kind permission of Josef Weisgram (Vienna); (I-P) Sternotherus carinatus (IW1145).

for each joint (Fig. 3A-D) and angles were measured using ImageJ. Angles on radiographs were measured directly.

Fossil and macerated vertebrae were manually moved against each other along the horizontal and vertical plane (Fig. 3A-D). The central articulations were always left articulated with one another (without space for intervertebral disc) and at least part of the zygapophyses was always left articulated. The "neutral" position is herein confirmed to be the maximum overlap of the articular facets of the zygapophyses (see Discussion section). The maximum dorsal and ventral movement was documented in lateral view by measuring the angle between ventral margins of the central bodies to the exclusion of ventral processes (Fig. 3A-C). The maximum amount of lateral motion was documented from dorsal view and angles were measured between the midlines of the neural arches (Fig. 3D).
Additional photographs were taken in anterior and posterior view of each vertebra and angles were measured between the centre of the centrum and the lateral most expansions of the articular facet of the zygapophyses (Fig. 3E, Supplementary Table S5).

For angles on radiographs (Supplementary Table 7A,C,D,F) and CT images (Supplementary Table 8A,B,F,G), measurements were also taken along the ventral line of the centra (in lateral view) and along the midline (neural spine or hypophyseal crest/process) in dorsal or ventral view. When necessary, the 3D mesh models were rotated to allow more accurate measurement of angles. For both types of neck retraction, a dorsal view was measured of the deformed neck to estimate spatial rotation.

The angles were taken with an accuracy of $0.1^{\circ}$ but an uncertainty of measurement of about \pm 1 can be assumed. The 

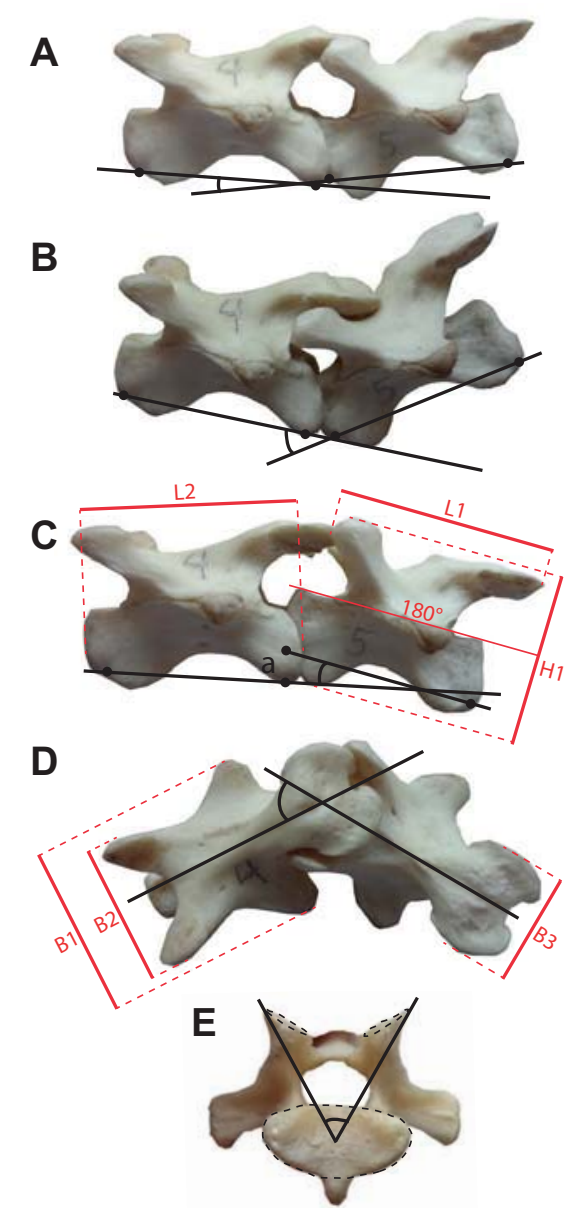

Figure 3. Definitions of angle measurements (raw mobility) and lengths. (A-D) Definition of angles exemplified by the 4th and 5 th cervical vertebrae of Phrynops geoffroanus (SMF 45470). Angles between vertebrae were measured along the ventral border of the centrals in lateral view and along the neural spines in dorsal view. Angle between vertebrae in (A) neutral position, (B) maximal dorsal flexion, (C) maximal ventral flexion, and (D) maximal lateral flexion. A direct contact of the centra and zygapophyses was allowed in osteological specimens, whereas in life images (X-rays/CTs) the natural conditions were measured, in which intervertebral disks are present. (E) Anterior face of the 7th vertebrae of $P$. unifilis (articular facets in dashed lines) and definition of the zygapophyseal angle. (C-D) In total, six morphometric lengths were measured for the macerated and fossil vertebrae using a digital caliper with an accuracy of $0.01 \mathrm{~mm}$. The measurements were rounded to $0.1 \mathrm{~mm}$ and correlated to each other (Supplementary Fig. S5, Supplementary Table S1 and S6). B1, maximum distance between the transverse processes; B2, maximum distance between the anterior zygapophyses; B3, maximum distance between the posterior zygapophyses; $\mathrm{H1}$, height (measured with the centrum oriented horizontally); L1, maximum length between zygapophyses; L2, length of centrum. fossil vertebrae used are all in good condition and most are symmetrical: erosion and deformation are therefore thought to be negligible.

\section{D-Scans and Animations}

Micro computed tomography $(\mu \mathrm{CT})$ was performed for selected vertebrae and associated skulls at the Steinmann-Institut für Geologie, Mineralogie \&t Paläontologie/Rheinische FriedrichWilhelms-Universität Bonn with a resolution of $187 \mu \mathrm{m}$ and at the Riedberg Campus of the Goethe-Universität Frankfurt with a resolution of about $25 \mu \mathrm{m}$. The CT-scanned files were imported to Geomagic Studio 11 (Geomagic_Inc. 2009) where the postprocessing was undertaken. Each scanned bone was loaded into the software separately in order to optimize computing capacity and to obtain full sight of each bone. The bone surface was smoothened to remove the step-like surface structures created by the CT scanning progress. Existing holes in the model surface were filled using curvature filling algorithms which generate smooth fills following the surface geometry to the highest possible degree. Furthermore, polygon spikes, non-manifold edges, self-overlaps, and small components such as isolated polygon relicts were removed in order to simplify and smoothen the polygon surface. Missing parts of fossil bones, such as zygapophyses or vertebral processes, were complemented by mirroring the non-deformed or not broken part from the opposite side of the vertebra (if present). The mirrored structure was connected to the existing bone surface by creating a Boolean Union between the existing vertebra model and the newly added parts. All isolated bones were saved and exported as Wavefront Object Files (OBJ).

In a second step, the cleaned and smoothed bone OBJs were imported into the CAD software Rhinoceros 3D (Robert_McNee1_Ct_Associates, 2003, November) where articulation and angulation were set up. For this purpose, the screen was split into four viewports (top, front, side, and perspective) which allowed precise model rotations along the main axes of the world coordinate system. Complex rotations were achieved by rotating around the $X-, Y$-, and $Z$-axis consecutively.

At first, a neutral pose of the cervical spine was modeled. Subsequently, calculated angles between the vertebrae were added in order to create different model poses. This was done in caudal to cranial direction-beginning at C8 and ending at C1. During the setup of a joint angle, all vertebrae cranial to this joint were grouped and moved together in order to avoid positioning errors.

Afterwards, color schemes were assigned to the different model poses and renderings of the different viewports were created using the integrated Rhinoceros 3D standard rendering tool.

\section{Taphonomic Distance}

To calculate the live neck performances in fossils, the theoretical (Supplementary Table S4) and actual (Supplementary Table S8) angles between vertebrae were compared (Supplementary Table S9) in the six extant turtle taxa (see Fig. 1) for which enough 
comparable data was available. Regressions were calculated using (1) all vertebra within the neck of particular species and (2) the same single vertebrae among all species. Contrary to the first approach, the second resulted in implausible calculations. That speaks for a deeper dependence of adjacent vertebrae along a single neck than a correlation of particular vertebrae between species.

Following the same steps, the mobility between the 8th cervical (CV8) and the 1st dorsal (DV1) vertebrae was calculated resulting in implausible results for dorsal-ventral mobility but plausible results for lateral mobility. This speaks for a different integration of CV8/DV1 during dorsal-ventral flexions than exists between the other neck vertebrae; for lateral vertebrae movement a continued equation in the relation of vertebra towards CV8/DV1 is plausible.

The regressions of theoretical against actual angles between the neck vertebrae (Supplementary Table S10) were used to calculate live neck performances in fossils (Supplementary Tables S11 and 12). The taphonomic distance was calculated for the cervical vertebrae in pleurodires, cryptodires, and all turtles combined (i.e., Testudines) separately. For all fossil taxa all three formulae were applied and, to decide for the most plausible movement, the following conservative assumptions were made (Supplementary Table S11): (1) The fossil neck vertebrae had the same relationships to each other as those of extant taxa (i.e., same formula;
Supplementary Table S10), (2) the measured angles should be larger than the calculated life-angles in most cases (i.e., only few overstretchings of adjacent vertebrae are allowed), and (3) in the case of two or three plausible movements, the largest differences to the meassured value are presumed to be less plausible than the smaller difference.

\section{RESULTS}

Raw Mobility of Turtle Necks

Herein, "raw mobility" is defined as the maximum amount of horizontal and vertical motion that is mechanically allowed between two vertebrae, measured in degrees relative to the "neutral position", which is defined as the vertebral position with the greatest zygapophyseal overlap (Fig. 3). The lowest dorsal, ventral, and lateral raw mobility is seen in stem turtles. Cryptodires have the greatest dorsal and ventral raw mobility, whereas pleurodires have the greatest lateral raw mobility (Fig. 4, Supplementary Figs. S1-3, and Table S4). Relative to the centra, the zygapophyses show the largest angles in cryptodires, whereas stem turtles and pleurodires have smaller angles. Greater angles are measurable in the zygapophyses of the more anterior vertebrae of all species. Greater angles can also be found in the zygapophyses of the more posterior vertebrae of cryptodires (Supplementary Fig. S4).

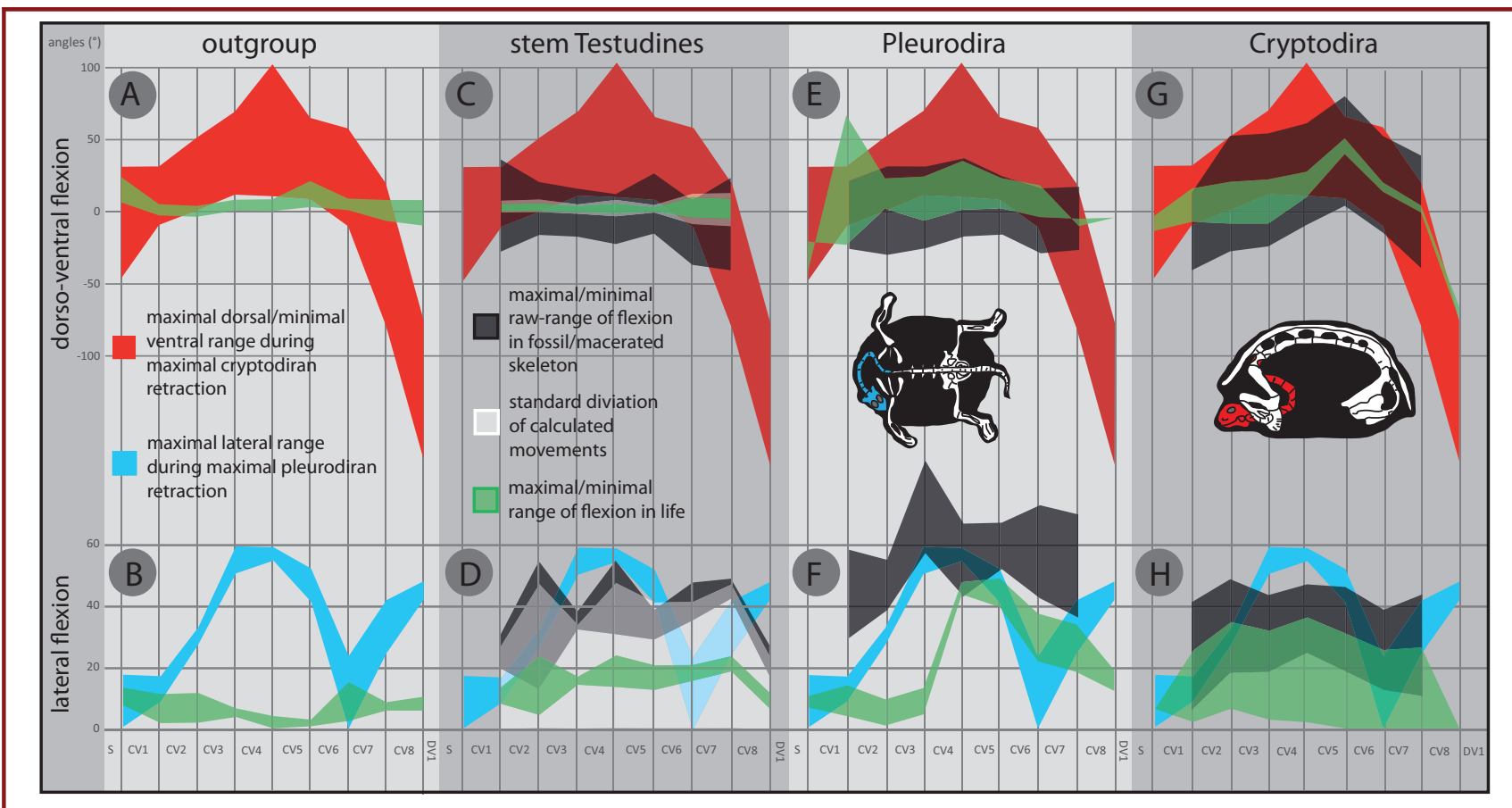

Figure 4. Neck movement calculated for fossil taxa compared to the maximal dorsoventral (top row) and maximal lateral flexions (below) measured for living species (compare Supplementary Tables S11 and S12). Images illustrate extant turtles at maximal retraction. Legend within the Figure. 
Within any given cervical column, the dimensions of the vertebrae are strongly correlated with one another (Supplementary Fig. S5). By contrast, the dimensions of a vertebra are only poorly correlated with its raw mobility and various measures of raw mobility only correlate poorly with one another. Stronger correlations exist between the neutral position of adjacent vertebrae and their related dorsal and ventral flexion (Supplementary Table S6).

Calculated Neck Mobility in Fossil Turtles

Three models of neck mobility were calculated for Pleurodira and Cryptodira separately and for both together (Testudines) that describe the taphonomic distance of the three groups (i.e., the difference between measured raw mobility and true mobility observed on radiographs and CT images) (Supplementary Table S7). The stem turtles Proganochelys quenstedti, Meiolania platyceps, and Naomichelys speciosa show dorsal and ventral neck flexion patterns that are consistent with the cryptodiran and pleurodiran models, respectively. The dorsal and lateral flexion of the neck of the paracryptodire Chisternon undatum is consistent with that of Pleurodira, whereas its ventral flexion is consistent with the patterns seen in both the Pleurodira- and Testudinesformulae. Finally, the basal stem-cryptodire Xinjiangchelys chowi exhibits a dorsal flexion that is consistent with that of Cryptodira, but whereas its ventral flexion is consistent with the Cryptodiraand Testudines-formulae, the lateral movement is more consistent with the pleurodiran mode (Fig. 7G,H). The best supported prediction of fossil movement is summarized in Supplementary Table S8.

The three models were used to predict the mobility between the eighth cervical vertebrae (CV8) and the first dorsal vertebrae (DV1) of fossil stem turtles. All models produced non-plausible results (i. e., negative motion; Supplementary Table 13) for dorsoventral mobility revealing that this joint is structurally different in basal turtles relative to all extant turtles. However, all models produce plausible results for lateral movement (Fig. 4D, Supplementary Table S9).

Outgroup representatives do not show sufficient flexibility to allow any movement resembling the neck retraction seen in extant turtles (Fig. 4A,B). The raw and calculated mobility of the vertebrae of all fossil turtles included in this study (incl. deviation) lies strongly below the ability needed for full cryptodiran retraction (Fig. 4C). Similarly, the raw and calculated mobility of these fossil turtles does not reach the maximum flexion between CV3-5 that would be needed for full S-shaped pleurodiran like retraction (Fig. 4D). It is therefore apparent that the fossil stem turtles included in our sample were not able to retract their necks, at least in the way that extant cryptodires and pleurodires do. Our observations and calculations additionally confirm that pleurodires are not mechanically able to retract their necks in the cryptodiran mode (Fig. 4E) and vice versa (Fig. 4H).
Hypermobility

As a whole, true dorsoventral mobility remains within the osteological confines set by the raw mobility. However, some pleurodires (Fig. 4E) and some cryptodires (Fig. 4G) have the ability to slightly overstretch particular joints (i.e., hypermobility) by disengaging the central articulations, particularly during extreme dorsoventral flexion (Fig. 20, Supplementary Figs. S10 and S11) while having the muscles and tendons maintain the integrity of the neck. The zygapophyses of two adjoining vertebrae never loose contact with one another during dorsoventral flexion.

During lateral flexion, the neck shows no (Fig. 4F) or only little hypermobility of adjacent vertebrae in pleurodires (Supplementary Fig. S12). In the most retracted neck condition of cryptodires, some vertebral centra show little "detachments" and in some specimens, the zygapophyses of CV8 and DV1 can detach as well. Naturally, the observed maximally retracted neck condition of cryptodires (Fig. 4) represents only the final stage of a "safetylinked bicycle chain"-like process of retraction (Herrel et al., 2008) while squeezing through the shell opening. Given that we only documented the end point during retraction in most species, it is plausible that other joints also show hypermobility during retraction. The large angle peak documented between CV4/CV5 in Figure 4G results from live angle measurements during trionychid retraction. As no detachment of vertebrae occurs in those species, a similar high raw mobility can be expected. Nevertheless, the articulation of vertebrae of up to $100^{\circ}$ must be associated with considerable dislocations of the intervertebral discs and deformations of the intervertebral capsule (Supplementary Fig. S11F).

\section{Modeling}

A 3D-model of the mobility of the neck of the Triassic stem turtle Proganochelys quenstedti indicates that this taxon was able to retract its head by tucking it sideways within the confines of the shell. In contrast to living pleurodires and cryptodires (Figs. 2G-H, M, 5C and D, and 6C and D), however, the retraction seen in $P$. quenstedti is achieved through a compound ventrolateral flexion, not through an S-shaped folding of the neck (Fig. 7). By contrast, cryptodiran like retraction can only be achieve by our model under highly unreasonable circumstances (i.e., $180^{\circ}$ rotation between the eighth cervical and first thoracic vertebrae and hypermobility along all cervical joints, Supplementary Fig. S9).

\section{DISCUSSION}

Reconstructing the Neutral Neck Position in Fossils

Given that the vast majority of fossil organisms do not display any "unusual" neck morphology, only little attention is generally accorded to mobility of this body region. A few notable exceptions nevertheless exist: humans, herbivorous mammals, crocodilians, birds, and other theropod dinosaurs (van der Leeuw et al., 2001a,b; Samman, 2013; Snively et al., 2013), and particularly sauropod 


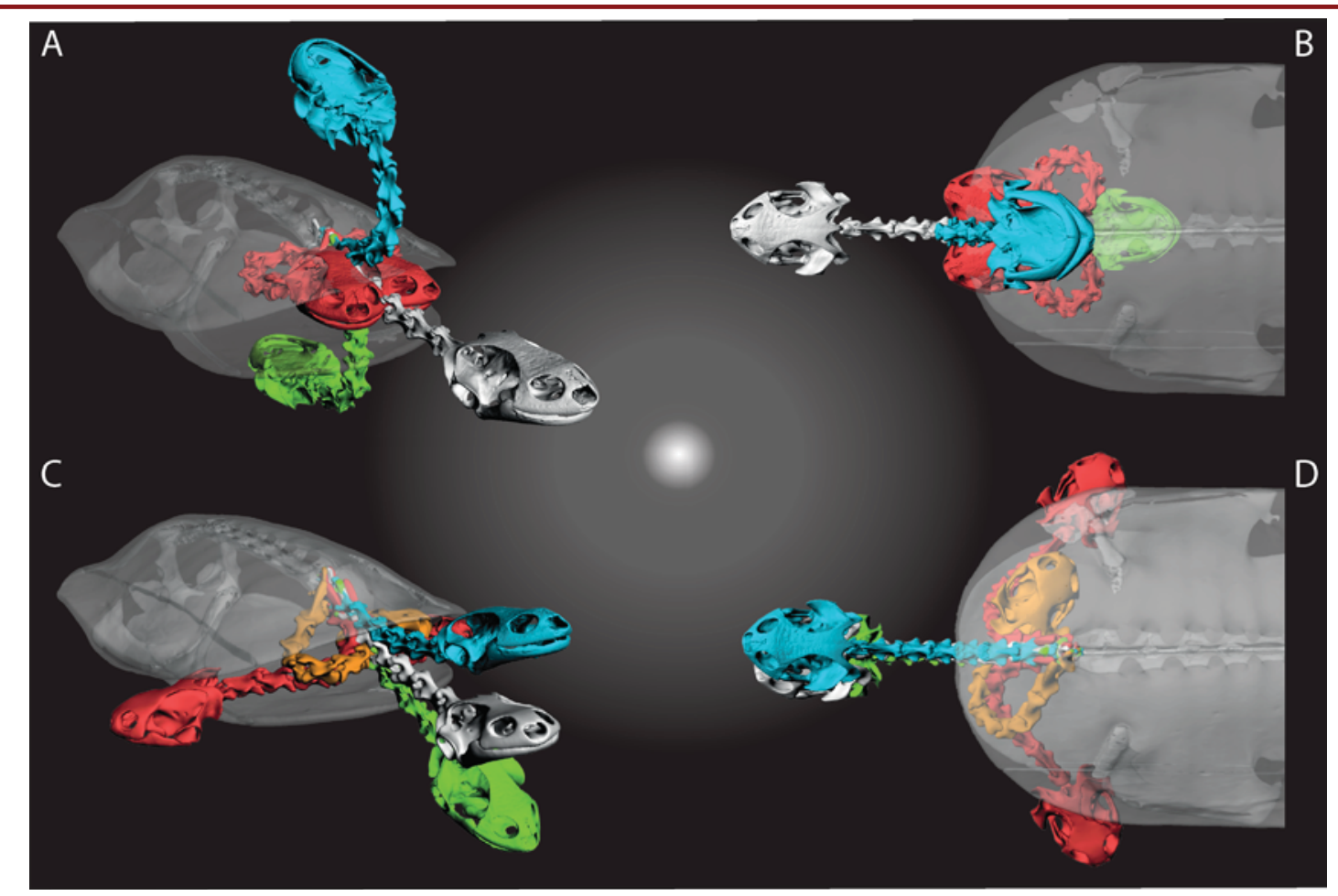

Figure 5. Comparison of raw (A,B: Phrynops geoffroanus) and life neck motion (C,D: Phrynops hilarii) of a pleurodire turtle. In P. hilarii, dorsal and ventral flexion are based on life-calculation (Supplementary Table S10), other neck positions are based on life-CT-data. $(A, C)$ frontolateral perspective view, $(B, D)$ dorsal view. Light blue=dorsal flexion, green=ventral flexion, red=lateral flexion (incl. rotation); orange $=$ retracted neck; light gray $=$ extended neck; gray transparent $=$ shell. For further illustrations see Supplementary Figure S6.

dinosaurs (Berthoz et al., '92). The neck of sauropod dinosaurs has been studied extensively because its great length raises many physiological and biomechanical questions. Given that sauropods are situated along the phylogenetic stem of birds (Aves) within Archosauria, a number of recent studies reconstructed the muscle and ligament system of the sauropod neck by phylogenetically bracketing (de Queiroz and Gauthier, '92; Witmer, '95) the morphology of extant birds and crocodilians (Wedel and Sanders, 2002; Tsuihiji, 2004). In addition, the research is informed through observations made from extant analogues such as the giraffe, camel, and ostrich (Dzemski and Christian, 2007; Cobley et al., 2013) or by reference to unique anatomical structures such as the extensive air sack system (Schwarz-Wings and Frey, 2008).

Much of the research is focused on two primary questions: (1) what was the resting position of the neck and (2) what was the possible range of motion. Particularly the first question is highly contentious. Stevens and Parrish ('99) suggested by reference to modern analogues that the resting position of sauropod dinosaurs should be reconstructed at the point where the pre- and postzygapophyses overlap two thirds, which they called the "neutral position." But this assumption was recently shown to be incorrect by Taylor et al. (2009) by explicit reference to modern analogues. Christian and Heinrich ('98) and Christian (2002), by contrast, argued that the resting position should be reconstructed where the stresses between the joints can be calculated to have been the least.

In extant turtles, the necks are naturally curved in the posterior half (Herrel et al., 2008) because the anterior carapacial edge does not allow a fully horizontal neck orientation. Our observation on the relaxed neck position of anesthetized turtles (CT-scan; Fig. 5-6) confirms the presence of this curvature. The vertebral centra therefore never align in a straight line with $180^{\circ}$ angles. CT-scans of turtles in this relaxed position furthermore reveal that the zygapophyseal facets almost fully overlap each other, that the central articulations fit snugly, and that intervertebral spaces are minimal (see Weisgram and Splechtna, '90: fig. 1b). We are able to reconstruct the characteristic bend of the turtle neck in disarticulated specimens, when adjacent zygapophyseal articular facets overlap another optimally. We therefore conclude that this is the "neutral" position in turtles. Our 


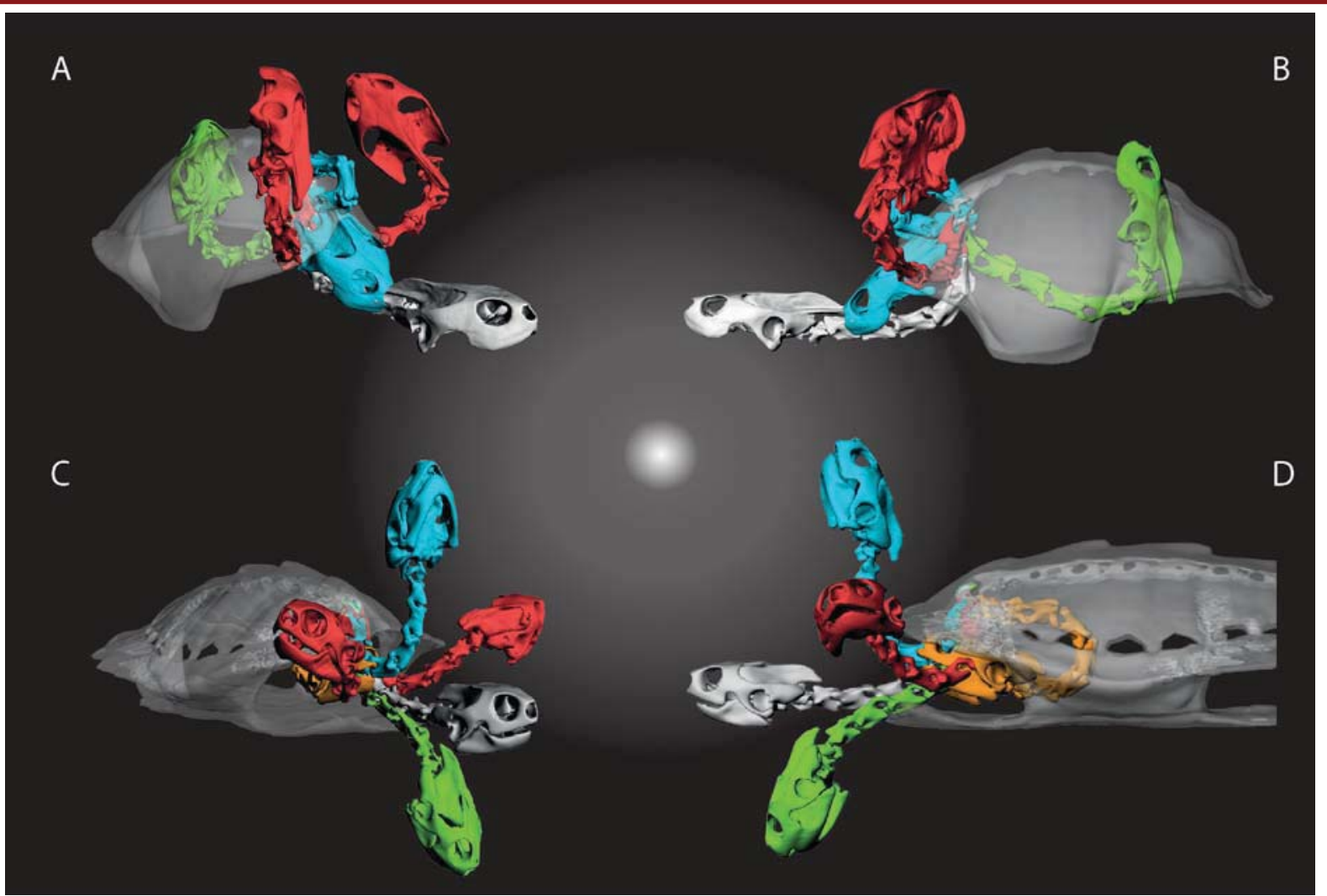

Figure 6. Comparison of neck motion in cryptodires illustrated in Malaclemys terrapin $(A, B)$ and Graptemys pseudogeographicus $(C, D)$ (both Emydidae) using combined live-CT-scans. $(A, C)$ frontolateral perspective view, $(B, D)$ lateral view. Color as in Figure 5 . For further illustrations see Supplementary Figure S7.

observations suggest that adjacent zygapophyseal facets should be modeled to overlap completely when reconstructing the neutral neck position in other fossil land vertebrates.

Predicting the Maximal Range of Motion in Fossils

There appears to be less contention regarding the reconstruction of the possible range of motion in fossil taxa, perhaps because it is always much greater than the preferred range of motion and because it is thought to be clearly constrained by the anatomy of the vertebrae. Stevens and Parrish ('99) reconstructed the possible range of motion of sauropods using 3D modeling techniques and constraints observed among extant birds, in particular the zygapophyseal capsule.

Turtles exhibit a wide variety of neck motions that must be considered extreme relative to other vertebrates. In addition to the "regular" retraction of the necks within the body cavity (either anterior to the rib cage, as in pleurodires, or within the ribcage between the shoulder girdles, as in cryptodires), turtles can "catapult" their necks over the shell for defence and perform extreme contortions with their neck when attempting to rectify themselves when lying on their backs. Our observations reveal that hypermobility (i.e., the dislocation of the joints) occurs during many of these extreme functions, but hypermobility also occurs during less extreme dorsoventral and lateral flexions. Although the unexpected hypermobility we found between the vertebrae of extant turtles can be ruled out as an autapomorphic feature of turtles, the ability of turtles to circumvent constraints imposed by their skeletal structure raises questions for modeling function in fossil vertebrates in general. At the very least, the ability of turtle to dislocated their central joints suggests that it is at least conceivable that other tetrapods, including sauropod dinosaurs, may have moved their necks slightly beyond the expected range of motion predicted by their bones to enable exceptional movement, for example, for reaching high and distant food resources, defence, uplifting, or body cleaning, and that these motions did not cause the death of an animal. As such, the results of our study can be understood as a test for the ductility of the central articular capsule, the spinal disk, and intervertebral muscles and tendons. 

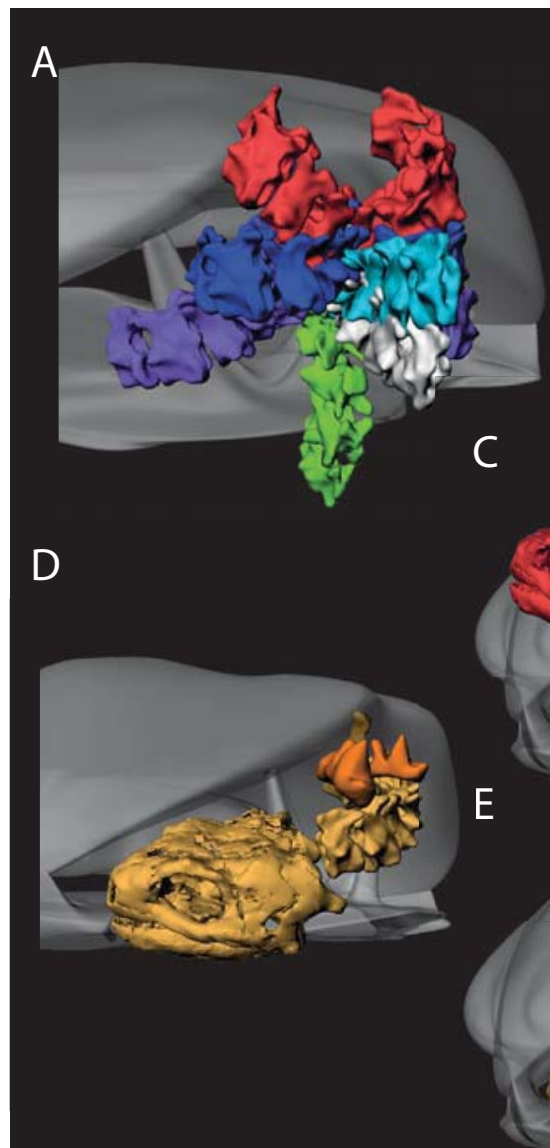

D
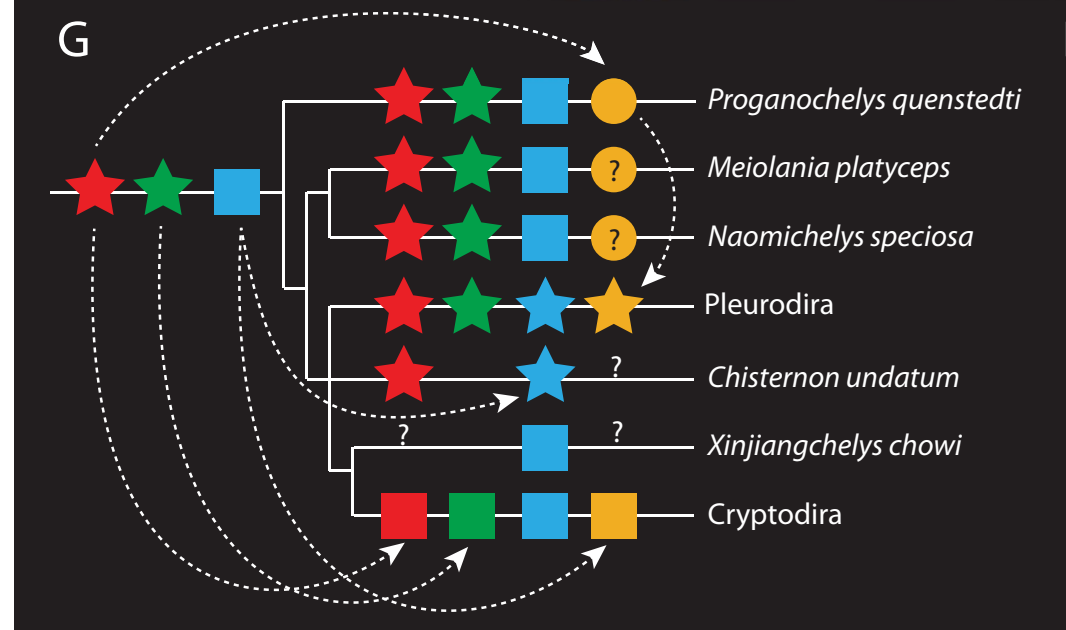

\section{$\mathrm{E}$}

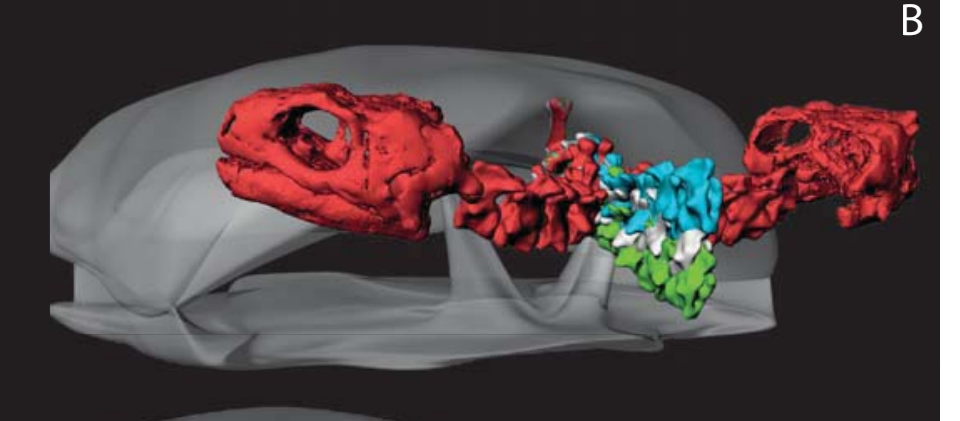

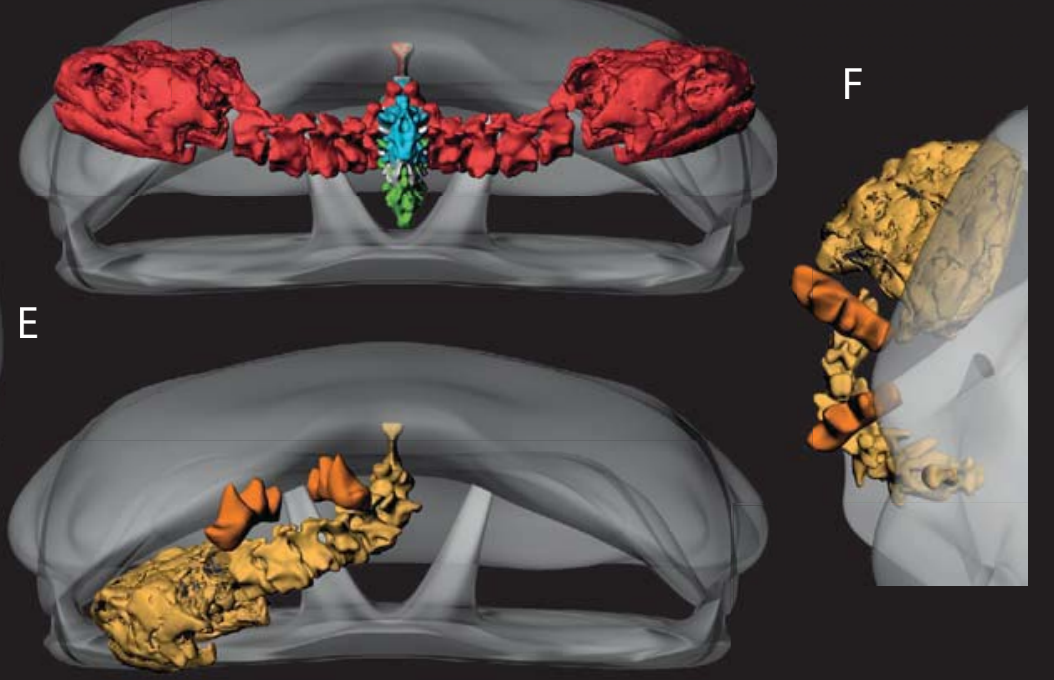

$x \rightarrow 1$

$\mathrm{H}$ pleurodiran mode

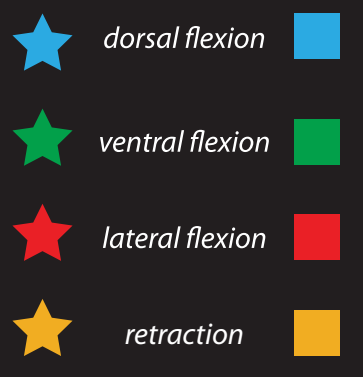

stem turtle mode

retraction

Figure 7. Reconstruction and animation of neck motion in the stem turtle Proganochelys quenstedti (SMNS 16980). (A) Anterolateral view; neck flections reconstructed using raw data. $(B, C)$ Neck flections using the calculated angles for life motion (Supplementary Table S12) in anterolateral (B) and frontal view (C); no rotation was allowed. (D-F) Reconstructed right-lateral retraction of the neck in (D) anterolateral, (E) frontal, and (F) dorsal view. Color code as in Figure 5, but here gray indicates neutral neck position. Dark blue in A shows lateral flexion with no rotation allowed. Dark orange = osteoderms on the neck. The atlas (CV1) was not reconstructed. For further details and discussion on the osteoderms see Supplementary Figures S8 and S9. (G) Hypothesized evolution of neck flexions and retractions in Testudinata. Dashed-line arrows indicate the hypothesized evolutionary changes. For further details see text. $(H)$ Legend to $(G)$. 
Evolution of Neck Movements Within Testudinata

We found five modes of neck movement among the studied groups of turtles (compare to Fig. 7G,H, Tables S7, and S8). As is well-known from studies on extant species, cryptodires (mode 1) are characterized by extreme dorsolateral movement to the neck, whereas pleurodires (mode 2) show extreme lateral movement. The relatively large and terrestrial stem turtles Proganochelys quenstedti, Meiolania platyceps, and Naomichelys speciosa (mode 3), by contrast, show a cryptodiranlike dorsal and a pleurodiran-like ventral and lateral flexion of the neck, but were unable to achieve neck-retraction in the modes seen in extant turtles. The baenid Chisternon undatum (mode 4) shows greater mechanical affinities with pleurodires, whereas the xinjiangchelyid Xinjiangchelys chowi (mode 5) shows greater mechanical affinities with cryptodires. Those findings are consistent with recent phylogenetic hypotheses that place $P$. quenstedti, M. platyceps, and N. speciosa along the stem of Testudines, that place baenid and xinjiangchelyid turtles closer to or at the base of the crown (Gaffney et al., 2007; Joyce, 2007; Anquentin, 2011; Sterli and de la Fuente, 2013), and that predict that the pure cryptodiran and pure pleurodiran neck flexion modes evolved independently within these lineages (Fig. $7 \mathrm{G}, \mathrm{H})$. Even though the necks of various fossil turtles are consistent in their morphology with those of extant turtles, it is important to emphasize that the mobility of all of their cervical joints was lower.

Retraction in Fossils

Although necks are available from a surprisingly large sample of taxa from the turtle stem lineage and the base of the crown, only few speculations have been made as to how these turtles moved their necks, beyond the conclusion that they could not withdraw their heads within their shells (e.g., Młynarski, '76). This conclusion is especially apparent for the basal stem turtles Proganochelys quenstedti and Palaeochersis talampayensis which possessed massive dorsal epiplastral processes that connected the plastron to the ribcage/carapace and physically hindered the head and neck from being withdrawn inwards as extant cryptodires do (Gaffney, '90; Sterli et al., 2007). The conclusion that other basal turtles were not able to withdraw their heads is in part based on the unspoken assumption that amphicoelous vertebrae cannot allow for great flexibility (see above; Gaffney, '90). Yet, the large pre- and postzygapophyses found universally among stem and basal turtles [(e.g., Meiolania platyceps (Gaffney, 1985, '90); Solnhofia parsonsi (Joyce, 2000); Plesiobaena antiqua (Brinkman, 2003); Xinjiangchelys chowi (Matzke et al., 2004)] reveal that some types of movement were possible and well-controlled.

Our study reveals that stem turtles show the same general mode of dorsal neck mobility that extant cryptodires do. However, to acquire the ability to retract their necks, cryptodires had to modify the vertebral shapes to enable even greater neck mobility and mostly had to evolve an extremely modified articulation between cervical vertebra 8 and dorsal vertebra 1 that allows folding the entire neck between the shoulder girdles. This specialized joint, characterized by the ventrally facing central articulation of the first thoracic vertebra, is universally absent among stem turtles, pleurodires, and most stemcryptodires (Gaffney et al., 2007; Joyce, 2007). The lateral flexion of stem turtles, in contrast, is pleurodiran-like. To achieve greater mobility, however, pleurodires modified some joints to form strong kinks, that is, the joints between cervical vertebra 5 and 6 (Weisgram and Splechtna, '90; Van Damme et al., '95) and cervical vertebra 8 and dorsal vertebra 1 (Fig. 4D). These specializations are universally lacking among stem turtles and all total group cryptodires. Although the modifications needed to achieve full cryptodiran and pleurodiran retraction should not be trivialized, the amount of precursor mobility already found in basal turtles is surprising.

The models we calculated for the neck movement of Pleurodira, Cryptodira, and all Testudines universally predicted implausible amount of movement (i.e., negative movement) for the important joint between cervical vertebra 8 and dorsal vertebra 1 in stem turtles (Supplementary Table S9). This suggests that the cervicodorsal joint has a different relationship to the neck vertebrae than the latter have among each other, and may indicate greater or reduced mobility at the neck/body-articulation in stem turtles relative to crown turtles.

Our 3D reconstruction of the skull, neck, and carapace of Proganochelys quenstedti allowed us to model neck movement for this taxon independent of our calculations. If the joint at the neck/ body-articulation is unreasonably allowed to rotate a full $180^{\circ}$, as in extant cryptodires, our simulations show that $P$. quenstedti still would require angles of more than $45^{\circ}$ between all cervical joints to achieve cryptodiran-like retraction, requiring extreme hypermobility for each joint (Supplementary Fig. S9). This reveals that this taxon is only able to achieve cryptodiran-like neck retraction under the most unlikely assumptions.

The dorsal process of the eighth cervical vertebra of $P$. quenstedti is well-developed and possibly attached firmly to a blunt process of the nuchal thereby restricting the mobility of this joint. If the position of the eighth cervical is fixed, our simulations confirm that the neck of $P$. quenstedti does not permit this taxon to retract its head below the shell like a pleurodire (i.e., with an Sshaped bend to the neck). But it was unexpected to discover that this taxon was able to retract its head, without the use of hypermobility, by tucking it sideways below the carapace in a combined ventrolateral motion (Fig. 7D-F).

The conclusion that $P$. quenstedti was able to retract its head and neck within the confines of the shell contradicts current orthodoxy that basal turtles had non-retractable necks (Hay, '08; Williams, '50; Młynarski, '76; Gaffney, '90), although we are unable to find any published rational explicitly justifying this conclusion. Instead, we suspect that low mobility was assumed to be present 
based on the combined presence of (1) amphicoelous vertebrae, which correlated with the presence of a stiffened vertebral column in many other groups of vertebrates (Romer, '56); (2) a fully roofed skull lacking temporal emarginations, which correlate among living turtles with the inability to retract their heads (Gaffney, '90; Werneburg, 2012); (3) large dorsal epiplastral processes, which span the anterior opening of the shell between the plastron and the carapace thereby mechanically restricting movement of the head between the shoulders (Gaffney, '90); and (4) cervical ribs and neck spines (Gaffney, 1975, '90), which may impair any extreme movements to the neck.

Our observations clearly contradict the hypothesis that amphicoelous vertebra are necessarily immobile and this observation may be important for assessing mobility in other groups of early reptiles. Similarly, although it is true that extinct turtles lack extended temporal emarginations, there is no obligatory or exclusive link between these two characters (Werneburg, 2012). Minute ventrolateral emarginations are nevertheless present (Jones et al., 2012; Werneburg, 2012), which further supports our model of lateral retraction in stem turtles. Living turtles with less mobile necks are universally macrocephalic and therefore physically unable to fit their heads within the anterior openings of their shells, and the loss of temporal emarginations in these taxa is likely necessary to protect the exposed neck from mammalian (Lyson and Joyce, 2009) or shark predators. The large dorsal epiplastral processes that block the anterior opening of the shell of $P$. quenstedti indeed pose an obstacle for cryptodiran like neck retraction, as the head is not able to fit between these bar-like processes, but our model demonstrates that the neck is able to elegantly bend around these structures.

Our model does not include the minute cervical ribs that decorate the neck of $P$. quenstedti (Gaffney, '90; Werneburg et al., 2013) and we are therefore not able to deduce their effect on neck mobility. However, well-developed cervical ribs are present among archosauromorphs (Nesbitt, 2011), particularly among longnecked protorosaurs (Wild, '73), but this group of reptiles are generally thought to possess highly mobile necks. Thus it is plausible that $P$. quenstedti was able to accommodate its significantly shorter ribs when tucking its head below the shell. The presence of two large neck-spines on the neck, the number of neck-spines actually associated with all known skeletons, does not impair retraction (Fig. 7D-F, Supplementary Fig. S9: see also discussion there). The skin is highly moveable against the underlying neck musculature in all extant turtles and other tetrapods (Werneburg, 2011). As such, we are confident that a flexible skin would have allowed the neck osteoderms to accommodate movement (in the sense of Jaekel ('15)) by shifting sidewards during retraction, which allows further protection of the laterally tucked neck.

The inference of full neck retraction in P. quenstedti should not come as a complete surprise, given that even the earliest turtles needed a minimally flexible neck to overcome restrictions imposed by the shell. Although the cervical mobility demanded to overcome this obstacle is much greater than found in the nonshelled outgroups, only a $100^{\circ}$ summed flexion formed by eight joints is needed to reach the early head-tuck combined with a dorsal roofing formed by the carapace. The complex S-shaped neck retraction of extant turtles only evolved later, perhaps as a way to accommodate significantly longer necks. The notion that even the most basal turtles (i.e., amniotes with a full turtle shell (Joyce et al., 2004)) were able to withdraw their head and neck within the confines of the shell therefore allow us to conclude that this feature evolved in certain synchrony with the origin of the turtle shell in the Middle to Late Triassic. The fossil turtle Odontochelys semitestacea (Li et al., 2008), which only evolved the plastron part of the shell, might have been able to tuck its neck similarly to what we modeled for $P$. quenstedti. Computer tomography of the former is currently not available and hence modeling is not possible. But given the documented rough similarity of its vertebral anatomy with P. quenstedti (Li et al., 2008), a similar neck mobility can be expected. However, whether the potential neck tucking (i.e., the modified lateral neck flexion) in 0 . semitestacea allowed any protection below its slightly broadened ribs-in the semantic sense of the word retractioncannot be evaluated herein. The same reservation holds true for potential sister taxa of turtles, such as Eunotosaurus africanus (Lyson et al., 2013), within or outside "Eureptilia”.

\section{ACKNOWLEDGMENTS}

We would like to thank Irina Ruf (Universität Bonn), Herbert Schwarz (Universitätsklinikum Tübingen), Joseph Weisgram (Universität Wien), Jan Prochel (Universität Tübingen), Anton Weissenbacher and Roland Halbauer (Tiergarten Schönbrunn, Wien), Katerina Harvati-Papatheodorou, and Wolfgang Gerber (Universität Tübingen) for enabling various aspects of this study. Carl Mehling (AMNH), Rainer Schoch (SMNS), Gunther Köhler, Linda Acker (SMF), and Philipe Havlik (Paleontological Collection, Tübingen) generously provided access to fossils and extant specimens in their care. Marcelo R. Sánchez-Villagra, Eric Snively, and three anonymous reviewers gave constructive suggestions to improve the manuscript. This project was funded by a grant from the Deutsche Forschungsgemeinschaft to W.G.J. (JO 928/1). The present study was discussed and approved by the institutional ethics committee of the University of Veterinary Medicine Vienna/ Austria in accordance with GSP guidelines and national legislation.

\section{LITERATURE CITED}

Anquentin J. 2011. Evolution and palaeoecology of early turtles: a review based on recent discoveries in the Middle Jurassic. Bull Soc Géol Fr 182:231-240.

Anquentin J. 2012. Reassessment of the phylogenetic interrelationships of basal turtles (Testudinata). J Syst Palaeontol 10:3-45. 
Berthoz A, Graf W, Vidal PP, editors. 1992. The head-neck sensory motor system. New York, Oxford: Oxford University Press.

Brinkman DB. 2003. Anatomy and systematics of Plesiobaena antiqua (Testudines: Baenidae) from the Mid-Campanian Judith River Group of Alberta, Canada. J Vertebr Paleontol 23:146-155.

Christian A. 2002. Neck posture and overall body design in Sauropods. Mitteilungen des Museums für Naturkunde Berlin, Geowissenschaftliche Reihe 5:271-281.

Christian A, Heinrich W-D. 1998. The neck posture of Brachiosaurus brancai. Mitteilungen des Museums für Naturkunde Berlin, Geowissenschaftliche Reihe 1:73-80.

Cobley MJ, et al. 2013. Inter-vertebral flexibility of the ostrich neck: implications for estimating sauropod neck flexibility. PLoS ONE 8: e72187; 1-10.

de Queiroz K, Gauthier J. 1992. Phylogenetic taxonomy. Annu Rev Ecol Evol Syst 23:449-480.

Dzemski G, Christian A. 2007. Flexibility along the neck of the ostrich (Struthio camelus) and consequences for the reconstruction of dinosaurs with extreme neck length. J Morphol 268:701-714.

Gaffney ES. 1975. A phylogeny and classification of the higher categories of turtles. Bull Am Museum Nat Hist 155:387-436.

Gaffney ES. 1985. The cervical and caudal vertebrae of the cryptodiran turtle, Meiolania platyceps, from the Pleistocene of Lord Howe Island, Australia. Am Museum Novit 2805:1-29.

Gaffney ES. 1990. The comparative osteology of the Triassic turtle Proganochelys. Bull Am Museum Nat Hist 194:1-263.

Gaffney ES, et al. 2007. Chubutemys, a new eucryptodiran turtle from the Early Cretaceous of Argentina, and the relationships of the Meiolaniidae. Am Museum Novit 3599:1-35.

Geomagic_Inc. 2009. Geomagic studio. Version: 11 SR 0.2. Rock Hill, SC: Geomagic Inc.

Hay OP. 1908. The fossil turtles of North America. Carn Inst Wash 75:1-568.

Herrel A, et al. 2008. Cervical anatomy and function in turtles. In: Wyneken J, Godfrey MH, Bels V, editors. Biology of turtles. Boca Raton, London, New York: CRC Press. p 163-185.

Hoffstetter R, Gasc JP. 1969. Vertebrae and ribs of modern reptiles. In: Gans AC, d'A Bellairs A, Parsons T, editors. Biology of the reptilia. vol 1. London, United Kingdom: Academic Press.

Jaekel 0. 1915. Die Wirbeltiere aus dem Keuper von Halberstadt, 08 Serie II, Testudinata. Paleont Z 2:88-214.

Jones MEH, et al. 2012. The head and neck anatomy of sea turtles (Cryptodira: Chelonioidea) and skull shape in Testudines. PLoS ONE 7:e47852.

Joyce WG. 2000. The first complete skeleton of Solnhofia parsonsi (Cryptodira, Eurysternidae) from the Upper Jurassic of Germany and its taxonomic implications. J Paleontol 74:684-700.

Joyce WG. 2007. Phylogenetic relationships of Mesozoic turtles. Bull Peabody Museum Nat Hist 48:3-102.

Joyce WG, et al. 2004. Developing a protocol for the conversion of rank-based taxon names to phylogenetically defined clade names, as exemplified by turtles. J Paleontol 78:989-1013.
Li C, et al. 2008. An ancestral turtle from the Late Triassic of southwestern China. Nature 456:497-501.

Lyson TR, Joyce WG. 2009. A new species of Palatobaena (Testudines: Baenidae) and a maximum parsimony and bayesian phylogenetic analysis of Baenidae. J Paleontol 83:457-470.

Lyson TR, et al. 2013. Evolutionary origin of the turtle shell. Curr Biol 23:1-7.

Matzke AT, et al. 2004. A new xinjiangchelyid turtle (Testudines, Eucryptodira) from the Jurassic Qigu Formation of the Southern Junggar Basin, Xinjiang, North-West China. Palaeontology 47:1267-1299.

Młynarski M. 1976. Testudines. Stuttgart, New York: Gustav Fischer Verlag.

Müller J, et al. 2010. Homeotic effects, somitogenesis and the evolution of vertebral numbers in recent and fossil amniotes. Proc Natl Acad Sci 107:2118-2123.

Nagashima $H$, et al. 2009. Evolution of the turtle body plan by the folding and creation of new muscle connections. Science 325:193196.

Nesbitt SJ. 2011. The early evolution of archosaurs: relationships and the origin of major clades. Bull Am Museum Nat Hist 352:1-292.

Ogushi K. 1911. Anatomische Studien an der japanischen dreikralligen Lippenschildkröte (Trionyx japanicus). I. Mitteilung. Morphol Jahrb 43:1-106.

Rieppel 0. 2008. The relationships of turtles within amniotes. In: Wyneken J, Godfrey MH, Bels V, editors. Biology of turtles. Boca Raton, London, New York: CRC Press. p 345-353.

Robert_McNeel_\&_Associates. (2003 November). Rhinoceros 3D. Version 3.0 SR3. Barcelona.

Romer AS. 1956. Osteology of the reptiles. Chicago, London: The University of Chicago Press.

Samman T. 2013. Tyrannosaurid craniocervical mobility: A preliminary assessment. In: Parrish JM, Molnar RE, Currie PJ, Koppelhus EB, editors. Tyrannosaurid paleobiology. Indiana: University Press. $p$ 195-210.

Schwarz-Wings D, Frey E. 2008. Is there an option for a pneumatic stabilization of sauropod necks?-an experimental and anatomical approach. Palaeontol Electron 11:17A:26p.

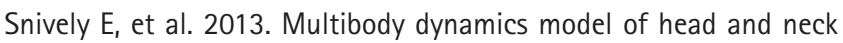
function in Allosaurus (Dinosauria, Theropoda). Palaeontol Electron 16:11A29p.

Sterli J, de la Fuente MS. 2013. New evidence from the palaeocene of patagonia (argentina) on the evolution and palaeo-biogeography of meiolaniformes (testudinata, new taxon name). J Systemat Palaeontol 11:835-852.

Sterli J, et al. 2007. Anatomy and relationships of Palaeochersis talampayensis, a Late Triassic turtle from Argentina. Palaeontogr Abt A 281:61.

Stevens KA, Parrish JM. 1999. Neck posture and feeding habits of two Jurassic sauropod dinosaurs. Science 284:798-800.

Taylor MP, et al. 2009. Head and neck posture in sauropod dinosaurs inferred from extant animals. Acta Palaeontol Pol 54:213-220. 
Thomson RC, Shaffer HB. 2010. Sparse supermatrices for phylogenetic inference: taxonomy, alignment, rogue taxa, and the phylogeny of living turtles. Syst Biol 59:42-58.

Tsuihiji T. 2004. The ligament system in the neck of Rhea americana and its implications for the bifurcated neural spines of sauropod dinosaurs. J Vertebr Paleontol 24:165-172.

Vaillant L. 1883. Disposition of the cervical vertebrae of chelonians. Am Nat 17:61-63.

Vaillant ML. 1881. Mémoire sur la disposition des vertebres cervicales chez les chéloniens. Ann Sci Nat Zool Paléontol 6:1-106.

Van Damme J, et al. 1995. Kinematics of the escape head retraction in the common snake-necked turtle, Chelodina longicollis (Testudines: Pleurodira: Chelidae). Belg J Zool 125:215-235.

van der Leeuw AHJ, et al. 2001. Control of the cranio-cervical system during feeding in birds. Am Zool 41:1352-1363.

van der Leeuw AHJ, et al. 2001. Evolutionary morphology of the neck system in ratites, fowl and waterfowl. Neth J Zool 51:243-262.

Wedel MJ, Sanders RK. 2002. Osteological correlates of cervical musculature in Aves and Sauropoda (Dinosauria: Saurischia), with comments on the cervical ribs of Apatosaurus. PaleoBios 22:1-6.

Weisgram J, Splechtna H. 1990. Intervertebral movability in the neck of two turtle species (Testudo hermanni hermanni, Pelomedusa subrufa). Zool. Jahrb. Abt. Anat. Ontog. Tiere 120:425-431.
Weisgram J, Zweers GA. 1987. Avian cranio-cervical systems, part II: arthology of the occipito-cervical system in the mallard (Anas platyrhynchos L.). Acta Morphol Neerl Scand 25:157-166.

Werneburg I. 2011. The cranial musculature in turtles. Palaeontol Electron 14:15a:99p.

Werneburg I. 2012. Temporal bone arrangements in turtles: an overview. J Exp Zool B Mol Dev Evol 318:235-249.

Werneburg I, et al. 2013. Embryonic remnants of intercentra and cervical ribs in turtles. Biol Open 2:1103-1107.

Wild R. 1973. Die Triasfauna der Tessiner Kalkalpen. 23. Tanystropheus longobardicus (Bassani) (Neue Ergebnisse). Schweiz Paläontol Abh 95:1-162.

Williams EE. 1950. Variation and selection in the cervical central articulations of living turtles. Bull Am Museum Nat Hist 94:509561.

Witmer LM. 1995. The extant phylogenetic bracket and the importance of reconstructing soft tissues in fossils. In: Thomason $J$, editor. Functional morphology in vertebrate paleontology. Cambridge, United Kingdom: Cambridge University Press. p 19-33.

\section{SUPPORTING INFORMATION}

Additional supporting information may be found in the online version of this article 